\title{
Genome-Wide Association of Rice Blast Disease Resistance and Yield-Related Components of Rice
}

\author{
Xueyan Wang, ${ }^{1,2,3}$ Melissa H. Jia, ${ }^{2}$ Pooja Ghai, ${ }^{2,4}$ Fleet N. Lee, ${ }^{1}$ and Yulin Jia ${ }^{2}$ \\ ${ }^{1}$ Rice Research and Extension Center, University of Arkansas, Stuttgart, AR 72160, U.S.A.; ${ }^{2}$ USDA Agricultural Research \\ Service Dale Bumpers National Rice Research Center, Stuttgart; ${ }^{3}$ College of life science, China Jiliang University, Hangzhou \\ 310018, China; ${ }^{4}$ Department of Biological Sciences, Arkansas State University, Jonesboro, AR 72401, U.S.A.
}

Submitted 13 July 2015. Accepted 4 August 2015.

\begin{abstract}
Robust disease resistance may require an expenditure of energy that may limit crop yield potential. In the present study, a subset of a United States Department of Agriculture rice core collection consisting of 151 accessions was selected using a major blast resistance $(R)$ gene, $P i$-ta, marker and was genotyped with 156 simple sequence repeat (SSR) markers. Disease reactions to Magnaporthe oryzae, the causal agent of rice blast disease, were evaluated under greenhouse and field conditions, and heading date, plant height, paddy and brown seed weight in two field environments were analyzed, using an association mapping approach. A total of 21 SSR markers distributed among rice chromosomes 2 to 12 were associated with blast resistance, and 16 SSR markers were associated with seed weight, heading date, and plant height. Most noticeably, shorter plants were significantly correlated with resistance to blast, rice genomes with Pi-ta were associated with lighter seed weights, and the susceptible alleles of RM171 and RM6544 were associated with heavier seed weight. These findings unraveled a complex relationship between disease resistance and yield-related components.
\end{abstract}

Plant disease resistance $(R)$ genes play a critical role in preventing pathogen infection. Upon recognition by $R$ genes, signaling for plant innate immunity is activated and transduced within plant cells (Dangl and Jones 2001). The hallmarks of plant disease $R$ responses include cell-wall strengthening, production of signaling molecules, and activation of complex preformed defense networks (Jones and Dangl 2006). These active defense responses require resources that may otherwise be used for crop productivity (Bergelson and Purrington 1996). A few such studies demonstrated that there was a cost for plants to express $R$ genes (Smedegaard-Petersen and Tolstrup 1985; Tian et al. 2003), but the genetic basis for yield-related components such as heading date, plant height, and seed weight or grain quality that may associate with disease resistance has not been explored.

The stability of one of the world's most important food crops-rice (Oryza sativa) — has been constantly challenged by rice blast disease. Blast disease is one of the most serious rice diseases caused by the fungus Magnaporthe oryzae. A rice

Corresponding author: Y. Jia; E-mail: yulin.jia@ars.usda.gov; Telephone: +1.870 .672 .9300 ext. 229; Fax: +1.870 .673 .7581$

*The $\boldsymbol{e}$-Xtra logo stands for "electronic extra" and indicates that six supplementary figures and two supplementary tables are published online.

This article is in the public domain and not copyrightable. It may be freely reprinted with customary crediting of the source. The American Phytopathological Society, 2015. variety with super yield and blast resistance would be profitable and marketable worldwide. Improving rice yield and blast resistance is critical for global food security. Biparental mapping has been effectively used to determine genetic resistance to blast disease. Resistance to $M$. oryzae mediated by major or minor $R$ genes or quantitative traits loci (QTL) or both in the rice germplasm have been mapped on all 12 rice chromosomes except for chromosome 3. Some of them, including Pi-ta, Pi-b, Pi-k, Pi36, Pizt, and pi21, have been cloned (Wang et al. 2014). $\mathrm{Pi}$-ta, $\mathrm{Pi}-\mathrm{b}, \mathrm{Pi}-\mathrm{k}$, and $\mathrm{Pi} 36$ are typical nucleotide binding site-type $R$ genes (Ashikawa et al. 2008; Bryan et al. 2000; Wang et al. 1999); however, the recessive allele pi21 is a novel form of QTL negatively associated with rice grain quality (Fukuoka et al. 2009).

Genome-wide association analysis (GWAS) has been recently used to examine the relationship among yield-related components of rice. Consequently, plant height, heading date, and single-kernel weight governed by complex QTL have also been mapped (Lee et al. 2014; Zhao et al. 2011). GWAS revealed noticeable associations of genetic markers with blast resistance. However, a genetic relationship between yield-related traits with blast resistance has not been carefully examined (Zhao et al. 2011), despite the mapping of numerous candidate genes underlying these traits and cloning of a few of them, including a major gene involved in short stature of plant height (SD1) (Spielmeyer et al. 2002).

In the southern United States and worldwide, the major $R$ gene $P i$-ta has been effectively deployed to prevent blast disease (Jia et al. 2004; Wang et al. 2010), however, crop yield potentials were not comparable to preferred high-yielding blastsusceptible cultivars such as 'Francis' (Moldenhauer et al. 2007). Analysis of a backcross population and elite rice varieties containing $P i$-ta revealed a large linkage block (Jia 2009; Jia et al. 2012; Lee et al. 2011), and it is unknown if the Pi-ta linkage block may inhibit yield potential. Using a $P i$-ta-specific DNA marker and pathogenicity assay with differential races, a subset of the rice germplasm, called the Pi-ta core, was established, and 89 of them were verified to contain Pi-ta (Wang et al. 2010). However, it remains to be determined if the Pi-ta core may contain additional blast $R$ genes that can be used to manage rice blast in the United States.

The objectives of the present study were i) to determine $R$ genes to the commonly found United States races (isolates) by the association mapping approach and ii) to determine potential correlation among blast resistance, plant height and heading date, and seed weight.

\section{RESULTS}

The structure of the Pi-ta core.

Population structure analysis revealed six subpopulations (Q6) in the Pi-ta core. By calculating the mean value of $-\mathrm{Ln}$ PD, $\Delta \mathrm{Ln}$ PD 
(Evanno et al. 2005), and the variation of Ln PD, Q5 to Q7 was reasonable for the collection (Fig. 1). Based on the phylogenetic tree constructed with the neighbor-joining method (Fig. 2A) and biological information of the material, six subgroups were determined. The indica group was clustered into four subgroups (purple, blue, yellow, and light blue) (Fig. 2A and B). We were unable to separate tropical and temperate japonica (red branch) due to a smaller number of japonica accessions. For the same reason, aus and aromatic were combined as one subgroup (green) and were located between indica and japonica. Q6 was used to construct the population structure of the Pi-ta core (Fig. 2B).

\section{Multiple new genetic markers associated with blast resistance.}

A total of 21 loci, distributed on chromosomes 2 to12, were associated $(P<1 \mathrm{e}-3)$ with resistance to the blast races IA45, IB1, IB45, IB49, IB54, IC1, IC17, IE1, IE1k, IH1, and IG1 and panicle blast, contributing 4 to $25 \%$ of total phenotypic variations (Table 1). The simple sequence repeat (SSR) marker RM3394 at $0.65 \mathrm{Mb}$ on chromosome 7 was strongly associated with resistance to the races IE1, IG1, and IH1 of $M$. oryzae. The 221-bp allele of RM3394 indicates resistance, and the 213-bp
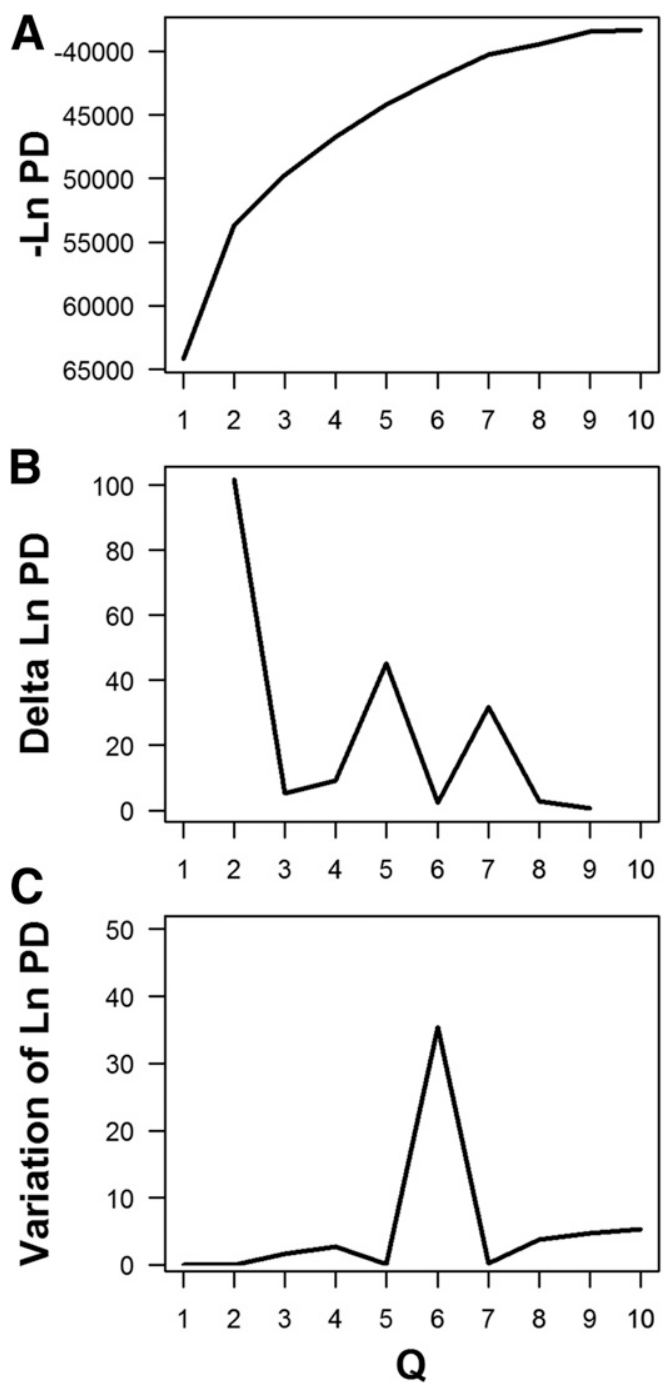

Fig. 1. Determination of the number of subpopulations. A, The plot of the mean value of the $-\mathrm{Ln}$ PD of each Q. B, The plot of the $\triangle \mathrm{Ln}$ PD calculated as described by Evanno et al. (2005). C, The plot of the variation of Ln PD of each Q. allele indicates susceptibility, respectively (Fig. 3A). The SSR markers RM232, RM6736, RM468, and RM514 at 9.75, 27.31, 32.68 , and $35.28 \mathrm{Mb}$ on chromosome 3 were associated with the blast races IC1, IA45, IH1, and IB49 with population structure $(\mathrm{Q})$ values of 4.93E-04, 1.03E-02, 2.44E-02, and 9.70E-03, respectively (Table 1 ).

\section{Multiple associated loci were colocated with the cloned blast $R$ genes.}

RM208 on chromosome 2, closely linked to the Pi-b gene, was associated with resistance to races IB49, IE1, IE1k, and IH1 of M. oryzae (Supplementary Fig. S1). The resistance allele was 179 bp (Fig. 3B). RM1359 and RM273, near the pi21 locus on chromosome 4 (Fukuoka et al. 2009), were associated with blast resistance to races IB1, IB49, IG1, and IH1 of M. oryzae. The resistant allele of RM273 was $210 \mathrm{bp}$. However, the resistance allele of RM1359 was not determined (Fig. 3C). RM1223 at $26.53 \mathrm{Mb}$ on chromosome 11, where Pik, Pikh, Piks, and Pikp located (Ashikawa et al. 2008; Sharma et al. 2005; Yuan et al. 2011; Zhai et al. 2011), was associated with resistance to races IC1, IC17, and IE1K of $M$. oryzae and early panicle blast. The resistance allele of RM1223 was a 164-bp fragment (Fig. 3D). Another closely linked marker, RM224 at $27.67 \mathrm{Mb}$ on chromosome 11, was associated with resistance to race IB54 of M. oryzae with resistant allele $131 \mathrm{bp}$ and early panicle blast with resistant alleles 143, 154, and 155, respectively (Table 1; Fig. 3D). RM7102 on chromosome 12, linked to the Pi-ta/Pi-ta2 locus, was associated with resistance to races IA45, IB45, and IC17 of M. oryzae. The size of the resistance allele was $190 \mathrm{bp}$ (Fig. 3E). Additionally, marker RM527, linked with the Pizt locus on chromosome 6 , was associated with race IB54 of M. oryzae, with a 233-bp resistant allele (Fig. 3F). It is notable that RM25, close to Pi36 on chromosome 8, was associated with both early and final panicle blast, though there was no clear resistant or susceptible allele of RM25 (Fig. 3G).

\section{Association analysis of yield-related components.}

The genetic markers explaining 6 to $19 \%$ of the phenotypic variation for plant height, heading date, and grain weight were identified by association analysis (Table 2). Among them, four SSR markers were associated with plant height, eight SSR markers were associated with heading date, and five SSR markers were associated with paddy and brown seed weight. RM431 at $38.89 \mathrm{Mb}$ on chromosome 1 associated with plant height in both 2002 and 2008 observations. RM254 at $24.23 \mathrm{Mb}$ on chromosome 11 was associated with both paddy and brown seed weight. The same region was also associated with seed weight in a previous study (Tanabata et al. 2012) (Supplementary Fig. S2). There were several SSR markers associated with heading date, but none of these markers were associated with heading date in studies conducted in 2002 and 2008.

\section{Genetic linkage between yield-related traits and blast resistance.}

The relationship between yield-related traits and blast resistance was analyzed with Pearson's correlation matrix (Fig. 4). Higher plant stature was significantly correlated with blast susceptibility. The presence of $P i$-ta had a significant negative correlation with paddy and brown seed weight, suggesting that the existence of $P i$-ta in a rice variety may produce lighter seeds. The existence of $P i$-ta was also negatively correlated with heading date in 2002 but not in 2008. It is worth mentioning that panicle blast was significantly correlated with all the races except IB54 of M. oryzae.

To unravel the relationship of yield-related components and blast resistance, we highlighted the markers associated with both yield-related components and blast resistance within $5 \mathrm{Mb}$ 
intervals (Fig. 5). RM171 on chromosome 10 associated with paddy seed weight and resistance to race IA45 of $M$. oryzae, RM6544 on chromosome 11 associated with paddy seed weight and resistance to race IH1 of M. oryzae, and RM7102 on chromosome 12 associated with heading date in 2002 and resistance to race IC17 of $M$. oryzae. These findings suggest that breeding for improved blast resistance may result in a yield penalty due to these genetic linkages.

\section{DISCUSSION}

The appropriate $Q$ value for GWAS analysis.

The number of the subpopulations selected is essential for the outcome of association. In the present study, a STRUCTURE (Fig. 1) analysis suggested that the Pi-ta core be separated into five, six, or seven groups. When $\mathrm{Q}$ increased from 5 to 6 , some of the associated markers appeared or disappeared (Supplementary Fig. S5). For example, RM1359 on chromosome 4 was not associated with any blast traits when Q was 5. However, this marker was associated with races IB1, IB49, IG1, and IH1 of $M$. oryzae when $\mathrm{Q}$ was 6 . Within the four indica subpopulations, RM1359 was associated with race IA45, IB1, IB45, IB49, IE1, IE1k, IG1, and IH1 of M. oryzae. We will overlook RM1359, which may associate with important blast resistance genes if we did not evaluate several $\mathrm{Q}$ values. In a recent study, $O$. sativa was separated into five subpopulations, indica, tropical japonica, temperate japonica, aus, and aromatic that are identical to subpopulations of 3,000 rice genomes determined with 20 million single nucleotide polymorphisms (Alexandrov et al. 2015). The structure of the Pi-ta core is similar to the reported.

\section{Multiple genetic loci associated with blast resistance.}

The SSR markers RM3394 on chromosome 7 and RM232, RM514, RM6736, and RM468 on chromosome 3 were associated with resistance to different blast races. These genetic associations have not been previously reported (Wang et al. 2014). Analysis of rice accessions carrying these markers in biparental mapping will help to determine if any of these markers will be mapped onto blast resistance QTL. The candidate genes can be predicted by estimating linkage disequilibrium of the genome region around the associated markers. For example, the candidate genes WRKY 29 (LOC_Os07g02060), serine/threonine kinase (LOC_Os07g02090), and RM3394 are within $192 \mathrm{~kb}$ (from 0.510 to $0.708 \mathrm{Mb}$ ) on chromosome 7 , based on 3,000 rice genomes (Supplementary Fig. S6). Association mapping, however, also identified genetic associations with six major blast $R$ genes, $P i-b, P i-k, P i-t a, P i-z t, P i 36$, and $p i 21$, a recessive QTL that is important for resistance to $M$. oryzae in the southern United States. RM208 on chromosome 2 near the $P i-b$ gene was associated with resistance to races IB49, IE1, IE1k, and IH1 of M. oryzae. A total of 26 accessions carried the 179-bp allele of RM208 in the Pi-ta core, 21 of them were determined to carry $P i-b$, as described by RoyChowdhury et al. (2012) and 25 of them were found to contain Pi-ta (Wang et al. 2010) (Fig. 3B). Excluding two accessions that were susceptible to IE1 and IE1K, the remaining accessions were resistant to IB49, IE1, IE1K, and IH1, suggesting that the 179-bp allele of RM208 is a useful marker for $P i-b$-dependent blast resistance consistent with previous studies (Fjellstrom et al. 2004; RoyChowdhury et al. 2012).

Association of RM1223 near the Pik gene with resistance to races IB54, IC1, IC17, and IE1 K of $M$. oryzae and early panicle blast suggests that the resistance spectrum of these RM1223containing rice accessions was conditioned by $P i k m / P i k h$ (Costanzo and Jia 2010). RM224, closely linked to RM1223, was also associated with resistance to race IB54 of M. oryzae and early panicle blast, suggesting that RM224 is a good marker for Pi-k, also consistent with a previous study (Fjellstrom et al. 2004). RM7102 on chromosome 12 near Pi-ta associated with resistance to races IA45, IB45, and IC17 of $M$. oryzae, suggesting that RM7102 can be a useful marker for the presence of Pi-ta, consistent with a previous study (Wang et al. 2010). The marker RM527 near the Pi-zt locus on chromosome 6 associated with race IB54 of $M$. oryzae, suggesting that the Pi-zt gene can be useful for blast management in the United States. However, a resistant allele, $233 \mathrm{bp}$ of RM527 identified from the present study, was not a resistant allele for Piz (RoyChowdhury et al. 2011), suggesting that RM527 may detect a different resistant allele at the $P i$-zt locus. We also found that the marker RM25 close to Pi36 was associated with resistance to early and final panicle blast of $M$. oryzae. Leaf blast reaction has been effectively used to predict resistance mediated by both major and minor blast $R$ genes. Early and final panicle blast ratings are often used as an additional insurance for breeders to select their breeding materials for blast resistance. Panicle blast

A
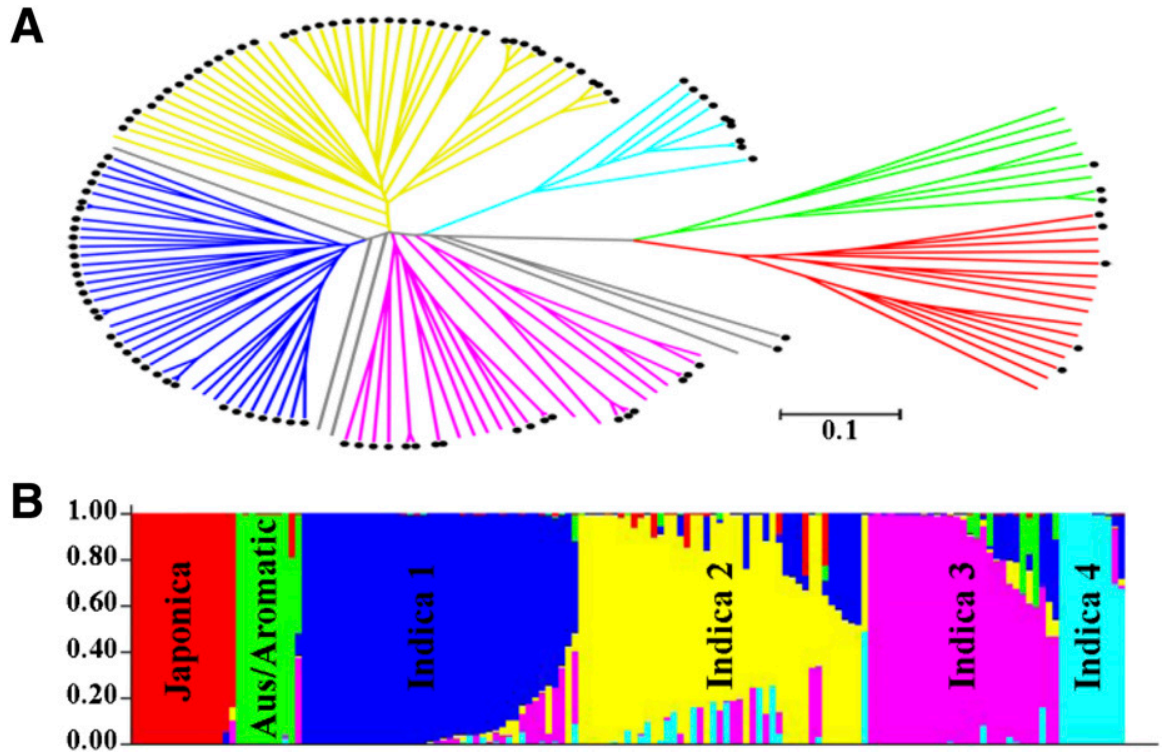

Fig. 2. The structure of the Pi-ta core. A, Phylogenic tree of the Pi-ta core. The black dots mark the accessions containing the functional Pi-ta gene. B, Population structure generated by the STRUCTURE software. The box shading corresponds to the branch shading in A. 
was significantly correlated with all the races except IB54, suggesting that IB54 is less competitive in the field. The Pi36 gene is an effective blast $R$ gene in Asia and it may be bred into rice germplasm. In fact, the $P i$-ta core consists of a relatively large number of accessions from Asia (Wang et al. 2010). Determination of resistance specificity with pathogenicity assays with differential blast races of Pi36 in biparental mapping using RM25 will be the next important focus.

The association of SSR markers RM1359 and RM273 on chromosome 4 with blast resistance is another important finding, because RM1359 is physically close to the pi2lgene (Fukuoka et al. 2009). The major QTL Pi21, originated from Japanese upland rice, was found in some japonica rice varieties. The recessive allele pi21, negatively associated with grain quality, is responsible for field blast resistance without hypersensitive response. Historically, upland rice has been used as a source of blast resistance in rice breeding programs since the 1920 s, but the pi21 gene has not been used in irrigated rice cultivars, possibly due to linkage drag resulting in poor grain quality (Hirochika et al. 2009; Jia 2009).

\section{Blast resistance and yield-related components.}

Negative linkage drags in relation to breeding objectives and pleotropic effects have been commonly documented in plant genetics (Brown 2002; Chen and Lübberstedt 2010). As mentioned earlier, the durable blast $R$ gene pi 21 has not been widely used because of tightly linked genes that affect desirable grain quality (Hirochika et al. 2009), not because of the pleiotropic effect of pi21 (Chen and Lübberstedt 2010; Tian et al. 2003). In the present study, RM431 at $38.89 \mathrm{Mb}$ on chromosome 1 was associated with plant height in both 2002 and 2008, observations that are consistent with several previous studies (He et al. 2001; Hittalmani et al. 2003; Lee et al. 2014; Lin et al. 2011; Septiningsih et al. 2003; Thomson et al. 2003; Yan et al. 1998). The semidwarf $S D 1$ gene is also located in the same region as RM431 (Spielmeyer et al. 2002). The SSR marker RM475, associated with blast resistance, is located within $5 \mathrm{Mb}$ of RM431, suggesting that a shorter plant is more resistant to blast disease (Fig. 5). The SSR marker RM254 at $24.23 \mathrm{Mb}$ on chromosome 11 was associated with both paddy and brown seed weight. The same region was also found to associate with seed weight by Tanabata et al. (2012). The SSR markers RM1223 and RM224 at Pi-k associated with blast resistance are within several megabases of this region (Fig. 5). On the same chromosome, the SSR marker RM6544 associated with resistance to race $\mathrm{IH} 1$ of $M$. oryzae and paddy seed weight. Taken together, these observations raise serious concerns that yield-related components and disease resistance are physically linked. In fact, the associated markers for blast resistance and yieldrelated components on chromosomes $2,3,5,7,10,11$, and 12 are within 5-Mb intervals (Fig. 5). Most importantly, SSR marker RM171 on chromosome 10 was mapped at a heading-

Table 1. The simple sequence repeat (SSR) markers linked to blast disease by the generalized linear model

\begin{tabular}{|c|c|c|c|c|c|c|}
\hline Chr. ${ }^{\mathrm{a}}$ & Loc. $(\mathbf{M b})^{\mathbf{b}}$ & Marker $^{c}$ & Traits $^{d}$ & $P$ value & $Q$ value & Phenotypic variation \\
\hline 2 & 20.4 & RM475 & IA45 & $9.84 \mathrm{E}-04$ & $1.90 \mathrm{E}-02$ & 0.08 \\
\hline 2 & 35.13 & RM208 & IB49 & $2.10 \mathrm{E}-04$ & $1.68 \mathrm{E}-02$ & 0.07 \\
\hline 2 & 35.13 & RM208 & IE1 & $1.65 \mathrm{E}-04$ & $1.03 \mathrm{E}-02$ & 0.09 \\
\hline 2 & 35.13 & RM208 & IE1K & $8.05 \mathrm{E}-06$ & $1.62 \mathrm{E}-03$ & 0.24 \\
\hline 2 & 35.13 & RM208 & IH1 & $8.26 \mathrm{E}-04$ & $1.19 \mathrm{E}-02$ & 0.08 \\
\hline 3 & 9.75 & RM232 & IC1 & $6.16 \mathrm{E}-06$ & 4.93E-04 & 0.15 \\
\hline 3 & 27.31 & RM6736 & IH1 & $5.17 \mathrm{E}-04$ & $1.03 \mathrm{E}-02$ & 0.07 \\
\hline 3 & 32.68 & RM468 & IB49 & $9.15 \mathrm{E}-04$ & $2.44 \mathrm{E}-02$ & 0.04 \\
\hline 3 & 35.28 & RM514 & IA45 & $1.18 \mathrm{E}-04$ & $9.70 \mathrm{E}-03$ & 0.10 \\
\hline 4 & 19.86 & RM1359 & IB1 & $8.46 \mathrm{E}-04$ & 4.70E-02 & 0.07 \\
\hline 4 & 19.86 & RM1359 & IB49 & $6.15 \mathrm{E}-04$ & $2.44 \mathrm{E}-02$ & 0.06 \\
\hline 4 & 19.86 & RM1359 & IG1 & $1.63 \mathrm{E}-04$ & $1.07 \mathrm{E}-02$ & 0.08 \\
\hline 4 & 19.86 & RM1359 & IH1 & 4.77E-04 & $1.03 \mathrm{E}-02$ & 0.08 \\
\hline 4 & 24.04 & RM273 & IG1 & $8.02 \mathrm{E}-04$ & $2.32 \mathrm{E}-02$ & 0.06 \\
\hline 4 & 24.04 & RM273 & IH1 & 8.93E-04 & $1.19 \mathrm{E}-02$ & 0.06 \\
\hline 5 & 18.11 & RM146 & IB45 & $3.01 \mathrm{E}-04$ & $1.26 \mathrm{E}-02$ & 0.08 \\
\hline 5 & 20.9 & RM161 & IH1 & $9.91 \mathrm{E}-06$ & $3.96 \mathrm{E}-04$ & 0.09 \\
\hline 6 & 9.86 & RM527 & IB54 & 7.73E-04 & 4.79E-02 & 0.14 \\
\hline 7 & 0.65 & RM3394 & IE1 & $6.11 \mathrm{E}-04$ & $2.54 \mathrm{E}-02$ & 0.09 \\
\hline 7 & 0.65 & RM3394 & IG1 & $2.09 \mathrm{E}-04$ & $1.07 \mathrm{E}-02$ & 0.08 \\
\hline 7 & 0.65 & RM3394 & IH1 & $7.51 \mathrm{E}-06$ & $3.96 \mathrm{E}-04$ & 0.12 \\
\hline 7 & 5.48 & RM125 & IE1 & $6.65 \mathrm{E}-05$ & 8.29E-03 & 0.09 \\
\hline 8 & 4.37 & RM25 & EPB & $4.62 \mathrm{E}-04$ & $1.20 \mathrm{E}-02$ & 0.17 \\
\hline 8 & 4.37 & RM25 & FPB & $3.21 \mathrm{E}-04$ & $6.42 \mathrm{E}-03$ & 0.2 \\
\hline 9 & 14.37 & RM409 & $\mathrm{IC} 17$ & $3.76 \mathrm{E}-05$ & 4.16E-03 & 0.07 \\
\hline 10 & 19.04 & RM171 & IA45 & 7.31E-04 & $1.90 \mathrm{E}-02$ & 0.06 \\
\hline 11 & 3.85 & RM6544 & IG1 & $1.70 \mathrm{E}-04$ & 2.32E-02 & 0.08 \\
\hline 11 & 11.85 & RM5857 & FPB & $6.56 \mathrm{E}-04$ & $6.56 \mathrm{E}-03$ & 0.25 \\
\hline 11 & 26.53 & RM1233 & EPB & 8.72E-04 & $1.38 \mathrm{E}-02$ & 0.15 \\
\hline 11 & 26.53 & RM1233 & IC1 & $9.78 \mathrm{E}-05$ & $3.91 \mathrm{E}-03$ & 0.08 \\
\hline 11 & 26.53 & RM1233 & IC17 & $9.34 \mathrm{E}-04$ & $3.45 \mathrm{E}-02$ & 0.07 \\
\hline 11 & 26.53 & RM1233 & IE1K & $2.30 \mathrm{E}-06$ & $6.13 \mathrm{E}-03$ & 0.13 \\
\hline 11 & 27.67 & RM224 & EPB & $2.49 \mathrm{E}-04$ & $1.20 \mathrm{E}-02$ & 0.23 \\
\hline 11 & 27.67 & RM224 & IB54 & $1.66 \mathrm{E}-06$ & $2.06 \mathrm{E}-04$ & 0.24 \\
\hline 12 & 13.21 & RM7102 & IA45 & $1.94 \mathrm{E}-04$ & $9.70 \mathrm{E}-03$ & 0.07 \\
\hline 12 & 13.21 & RM7102 & IB45 & $6.08 \mathrm{E}-05$ & $5.11 \mathrm{E}-03$ & 0.09 \\
\hline 12 & 13.21 & RM7102 & IC17 & $3.44 \mathrm{E}-05$ & $3.45 \mathrm{E}-02$ & 0.10 \\
\hline
\end{tabular}

a Chr. = chromosome

${ }^{\mathrm{b}}$ Physical location of the markers; $\mathrm{Mb}=$ mega-base pair.

c SSR marker.

d IA45, IB1, IB45, IB49, IB54, IC1, IC17, IE1, IE1K, IH1, and IG1 were the different blast races used in the greenhouse assay. EPB = early panicle blast and $\mathrm{FPB}=$ final panicle blast. 
date QTL by numerous studies (Doi et al. 2004; Li et al. 2003; Thomson et al. 2003; Lee et al. 2014; Lu et al. 1997). Instead of heading date, this marker associated with resistance to race IA45 of $M$. oryzae and also with lighter paddy seed weight. Cultivars expressing $P i$-ta are not competitive in yield potential compared with a rice cultivar without $P i-t a$, such as 'Francis' (Moldenhauer et al. 2007), because of a large linkage block at the Pi-ta locus (Jia, 2009). It is also known that linkage disequilbrium decay occurs within $75 \mathrm{~kb}$ in indica rice (Mather et al. 2007), suggesting a potential breeding opportunity.

To determine if associated SSR markers might be useful for plant breeding, we compared the presence or absence of resistant or susceptible alleles in 17 resistant accessions and 21 susceptible accessions to all races. The resistant alleles were only amplified from the accessions that are resistant to all races tested, indicating that rice germplasm carrying the resistance alleles is potentially resistant to blast (Supplementary Table S2). These findings suggest that the presence of these associated SSR markers is a useful indicator for blast resistance and these DNA marker profiles can be recommended as a predictor for genomic selection. Thus far, more than ten rice cultivars with $P i$-ta have been released to manage blast disease in the United States; however, yield of rice cultivars carrying $P i$-ta is not competitive compared with top-yielding rice cultivars and, therefore, their continued commercialization has been limited (Wang et al. 2010). In the present study, for the first time, we
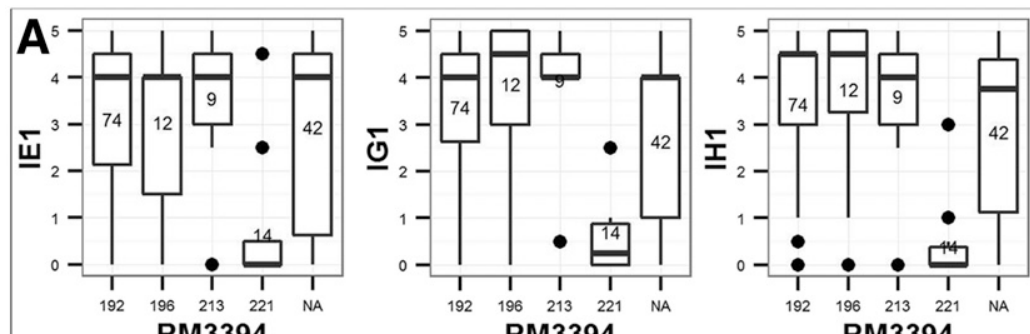

RM3394
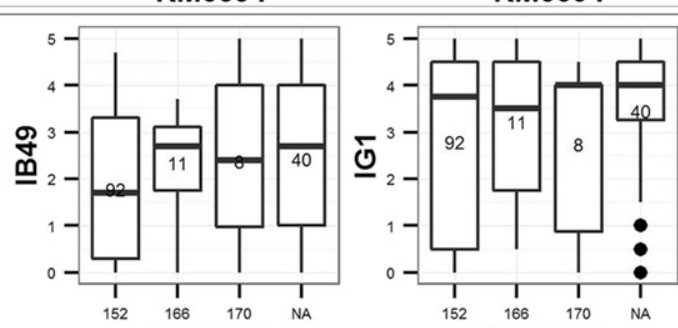

RM1359
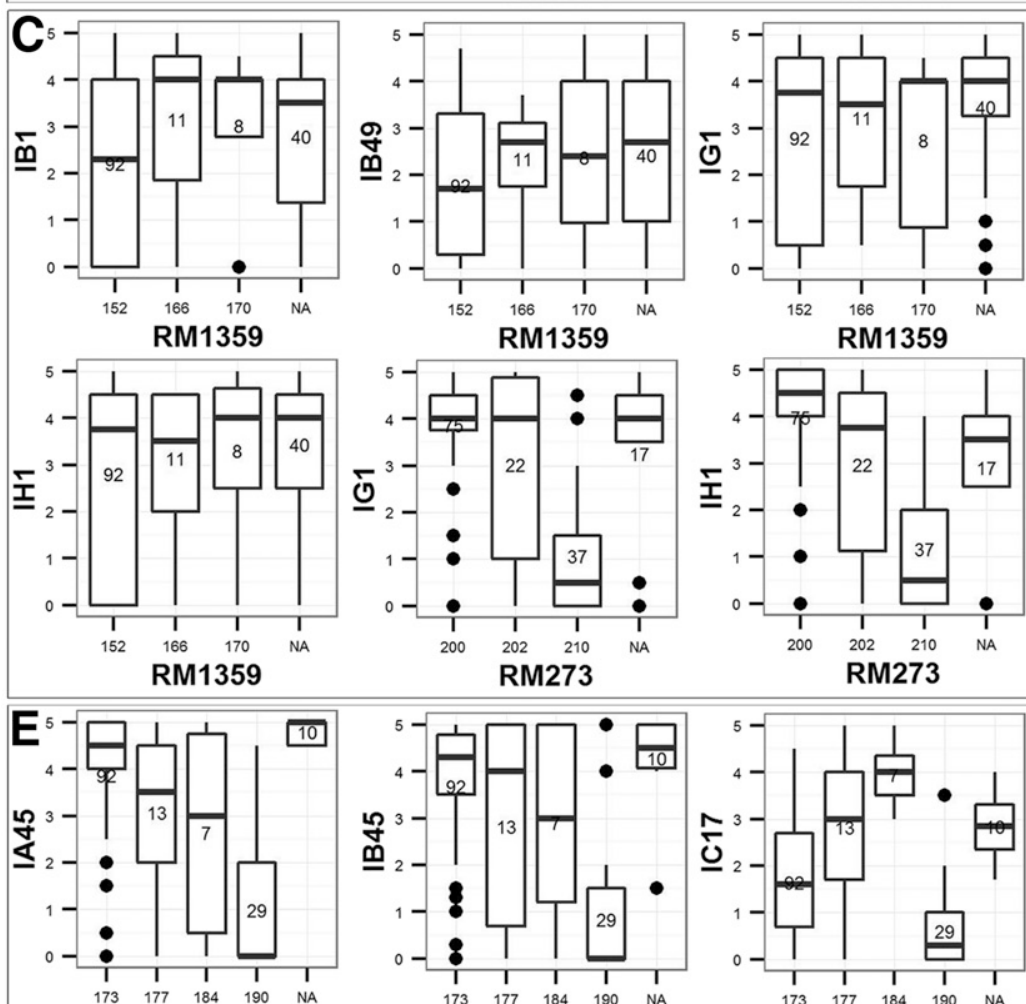

RM7102

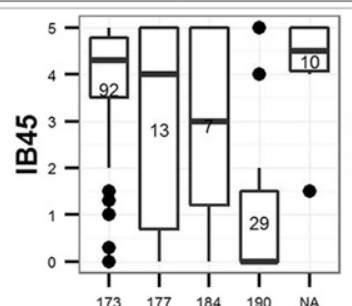

RM7102

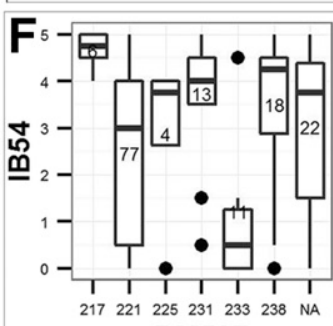

RM527

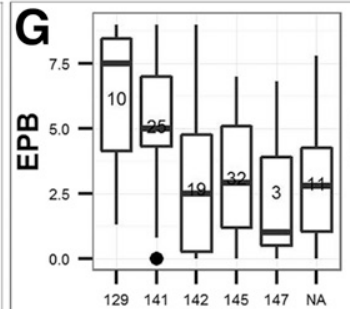

RM25

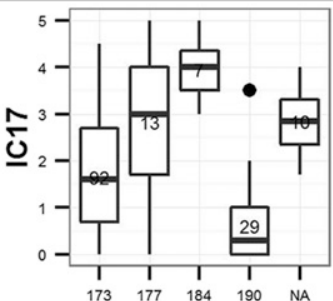

RM7102

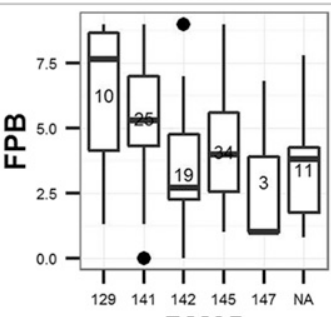

RM25

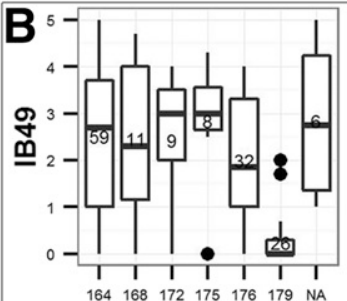

RM208

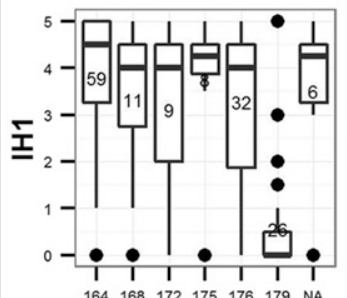

RM208

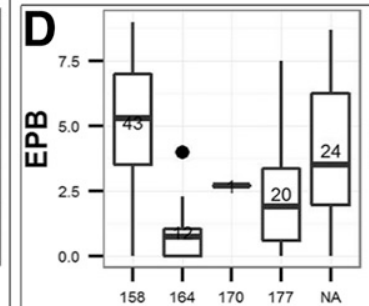

RM1233

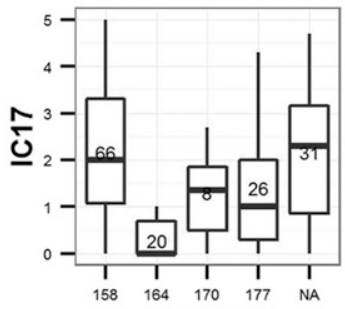

RM1233

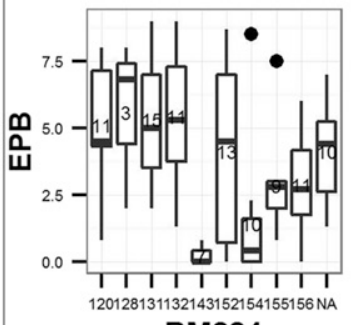

RM224

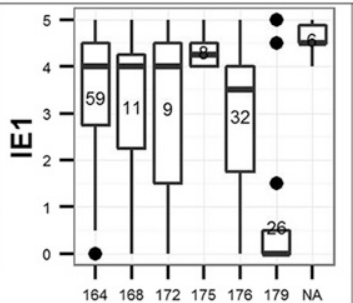

RM208

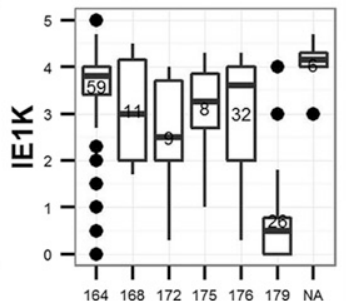

RM208

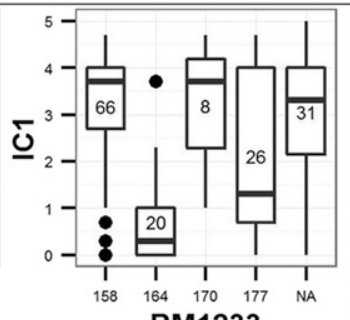

RM1233

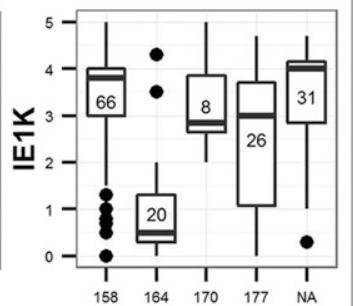

RM1233

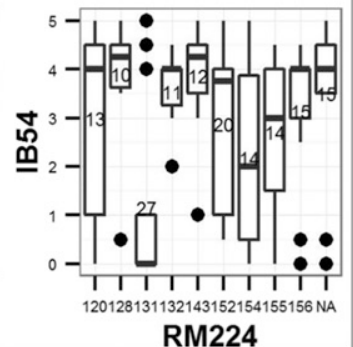

Fig. 3. A to G, Phenotypic variation (or value or range) of each allele of the associated markers tightly linked with the cloned resistance (R) genes. The $x$ axis references the size of the alleles (bp), the $y$ axis references the disease score. The bottom and top of the box are the first and third quartiles, and the band inside the box is the median. The ends of the whiskers represent the lowest datum still within 1.5 interquartile range (IQR) of the lower quartile, and the highest datum still within 1.5 IQR of the upper quartile. The dots are outliers. Numbers in the squares indicate the total number of lines carrying the predicted alleles. 
established that the shorter plant was associated with blast resistance. Shorter plants carrying semidwarf gene $S D 1$ were also associated with fissure resistance (Pinson et al. 2012). Both studies support a hypothesis that fissure and blast resistance may have been incorporated into the rice germplasm via introduction of SD1 during 'green revolution' through classical rice breeding. However, the negative association of Pi-ta with paddy and brown seed weight suggests that the existence of $P i$-ta in a rice variety may produce lighter seeds, resulting in lower yield. Additionally, the existence of Pi-ta was negatively correlated with heading date in the 2002 observation, suggesting that $P i$-ta-carrying rice varieties may also need a shorter

Table 2. The simple sequence repeat (SSR) markers linked to plant height, heading date, and brown and rough seed weight by the generalized linear model

\begin{tabular}{|c|c|c|c|c|c|c|}
\hline Chr. $^{\mathrm{a}}$ & Loc. $(\mathbf{M b})^{\mathbf{b}}$ & Marker ${ }^{c}$ & Traits $^{d}$ & $P$ value & $Q$ value & Phenotypic variation \\
\hline 1 & 6.67 & RM490 & PH 02 & 7.73E-04 & $2.899 \mathrm{E}-02$ & 0.06 \\
\hline 1 & 38.89 & RM431 & PH_02 & $1.03 \mathrm{E}-05$ & $7.725 \mathrm{E}-04$ & 0.09 \\
\hline 1 & 38.89 & RM431 & PH_08 & $4.66 \mathrm{E}-04$ & $2.982 \mathrm{E}-02$ & 0.10 \\
\hline 2 & 1.08 & RM154 & HD_08 & $8.17 \mathrm{E}-06$ & $8.388 \mathrm{E}-04$ & 0.19 \\
\hline 2 & 19.34 & RM341 & $\mathrm{BSW}$ & $3.04 \mathrm{E}-04$ & $1.727 \mathrm{E}-02$ & 0.14 \\
\hline 2 & 30.53 & RM530 & PH 08 & $9.24 \mathrm{E}-05$ & $1.183 \mathrm{E}-02$ & 0.13 \\
\hline 3 & 4.33 & RM489 & PH_08 & 7.16E-04 & $3.169 \mathrm{E}-02$ & 0.10 \\
\hline 3 & 31.39 & RM8203 & HD_02 & 7.39E-04 & $1.070 \mathrm{E}-02$ & 0.11 \\
\hline 5 & 22.22 & RM5401 & HD_02 & $9.88 \mathrm{E}-04$ & $1.070 \mathrm{E}-02$ & 0.11 \\
\hline 7 & 6.06 & Rid12 & $\mathrm{BS} \overline{\mathrm{W}}$ & $8.24 \mathrm{E}-04$ & $1.868 \mathrm{E}-02$ & 0.07 \\
\hline 7 & 6.06 & Rid12 & HD_02 & 8.67E-04 & $1.070 \mathrm{E}-02$ & 0.06 \\
\hline 7 & 19.25 & RM11 & HD_08 & $9.26 \mathrm{E}-04$ & $3.169 \mathrm{E}-02$ & 0.15 \\
\hline 9 & 21.52 & LJSSR1 & HD_02 & $1.18 \mathrm{E}-04$ & 4.196E-03 & 0.14 \\
\hline 9 & 22.2 & RM6816 & HD_02 & $8.75 \mathrm{E}-04$ & $1.070 \mathrm{E}-02$ & 0.07 \\
\hline 10 & 19.04 & RM171 & PSW & 7.36E-04 & $1.241 \mathrm{E}-02$ & 0.11 \\
\hline 11 & 3.85 & RM6544 & PSW & $7.98 \mathrm{E}-04$ & $1.241 \mathrm{E}-02$ & 0.12 \\
\hline 11 & 24.23 & RM254 & BSW & $5.08 \mathrm{E}-04$ & $1.727 \mathrm{E}-02$ & 0.13 \\
\hline 11 & 24.23 & RM254 & PSW & 3.44E-04 & $1.241 \mathrm{E}-02$ & 0.13 \\
\hline 12 & 13.21 & RM7102 & HD_02 & $1.64 \mathrm{E}-06$ & $1.166 \mathrm{E}-04$ & 0.16 \\
\hline
\end{tabular}

a Chr. = chromosome.

${ }^{\mathrm{b}}$ Physical location of the markers; $\mathrm{Mb}=$ mega-base pair.

c SSR marker.

${ }^{\mathrm{d}} \mathrm{PH}=$ plant height, $\mathrm{HD}=$ heading date, $\mathrm{PSW}=$ paddy seed weight, $\mathrm{BSW}=$ brown seed weight, $02=$ observation in 2002, AND $08=$ observation in 2008.
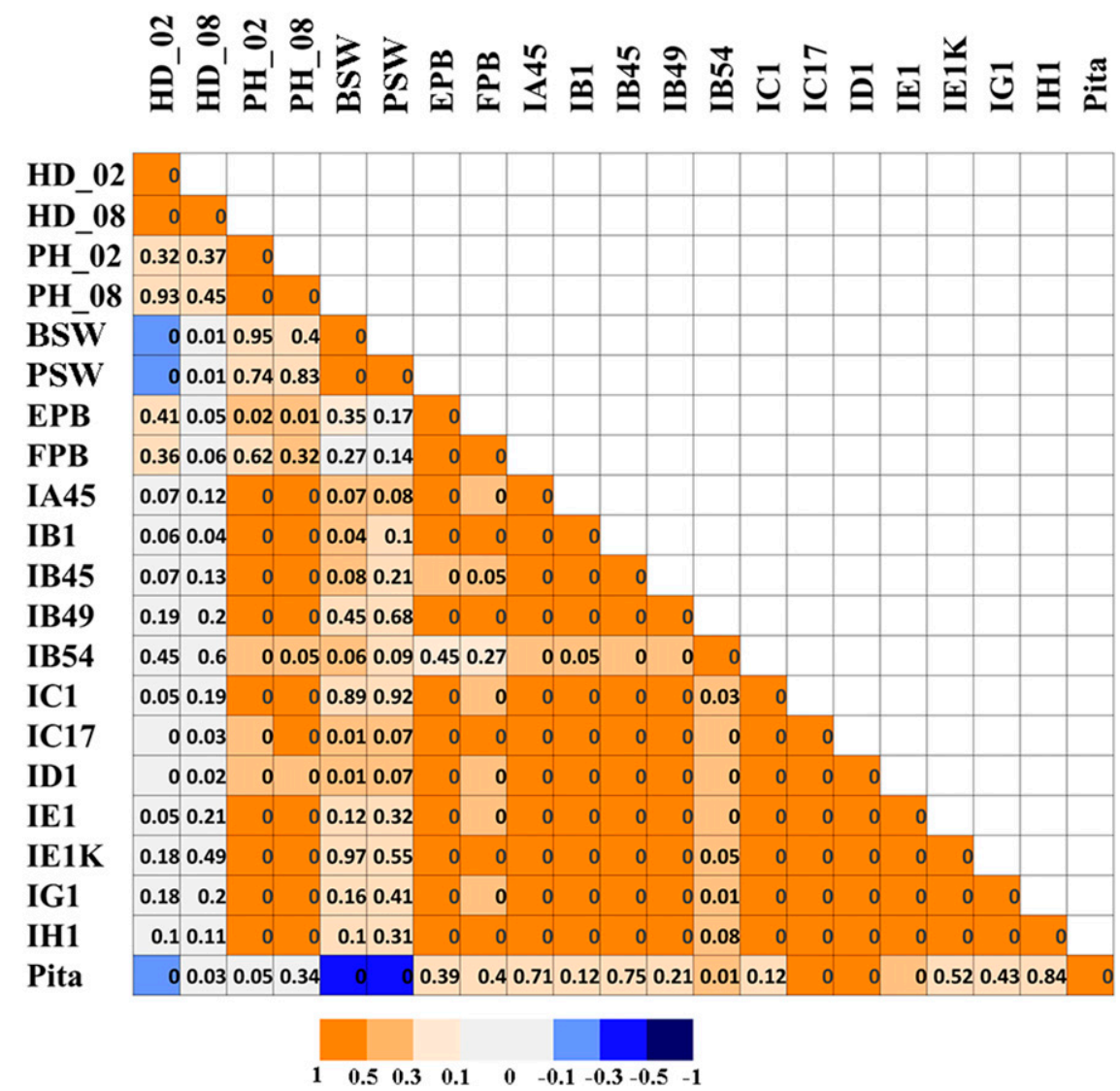

Fig. 4. Pearson's correlation matrix for all traits plus presence of $P i$ - $t a$. The shaded scale refers to the strength of correlation. In Pearson's correlation, abs $r=0.5$ to 1 means greater correlation, abs $r=0.3$ to 0.5 means medium correlation, abs $r=0.1$ to 0.3 means lesser correlation, and abs $r=0$ to 0.1 means no correlation. The numbers are $P$ values to accept or reject the correlation between two traits. 
production period. Further analysis of the associations identified by this study will help rice breeders to breed for highyielding and disease resistant crops and also will help to determine any genetic basis interplaying blast resistance and yield-related components.

For association studies, using 0.05 as cutoff for the $\mathrm{Q}$ value to adjust the $P$ value of each association marker by the false discovery rate (FDR) approach often will reduce false positives (Storey and Tibshirani 2003). However, we observed many more associated markers with both blast disease and yield-related components, using FDR. Some associated genetic markers may not have any biological relevance, suggesting that the 0.05 cutoff for FDR was still not stringent enough. In fact, the default cutoff $P$ value of 0.001 in TASSEL was suitable and was used to identify the associated markers in this report.

\section{Summary.}

We established a link between rice yield-related components with disease resistance through association study. This new finding will need to be validated using different molecular techniques. Exploration of the genetic relationship of agronomic traits with disease resistance will not only help breeders to develop winning rice cultivars, it will also help to improve understanding of the molecular basis of plant immunity and productivity. Ultimately, this new knowledge will aid in the development of a toolbox for in silico crop improvement in the future (Spindel et al. 2015).

\section{MATERIALS AND METHODS}

Fungal materials and disease evaluation in greenhouses and in fields.

Twelve $M$. oryzae isolates belonging to races IA45, IB1, IB45, IB49, IB54, IC1, IC17, ID1, IE1, IE1k, IG1, and IH1 were used for disease evaluation. $M$. oryzae isolates were grown on oatmeal agar plates (Difco, Detroit) for 7 days at 21 to $24^{\circ} \mathrm{C}$ under dark and white florescent light before inoculation. For each rice accession, 10 to 15 seeds were sowed into a black plastic insert $(3.8 \times 3.8 \mathrm{~cm})$ with holes at the bottom. A total of 72 inserts with seeds and soil were randomly placed in a tray $(25.4 \times 50.8 \mathrm{~cm})$ and were grown at $25^{\circ} \mathrm{C}$ with a 8 -h light and 16-h dark cycle in a greenhouse. The seedlings were treated using the following procedure when most of them reached the 3- to 4-leaf stage (approximate 18 days after sowing): i) M. oryzae spores on oatmeal plates were washed with $2 \%$ gelatin containing sterilized deionized $\mathrm{H}_{2} \mathrm{O}$; ii) $M$. oryzae spores were counted, using a hemacytometer under a microscope, and were adjusted to $10^{5}$ spores per milliliter, with gelatin containing the solution mentioned before; iii) each tray was inoculated with $25 \mathrm{ml}$ of spore suspension, using an artist airbrush; and iv) the plants were

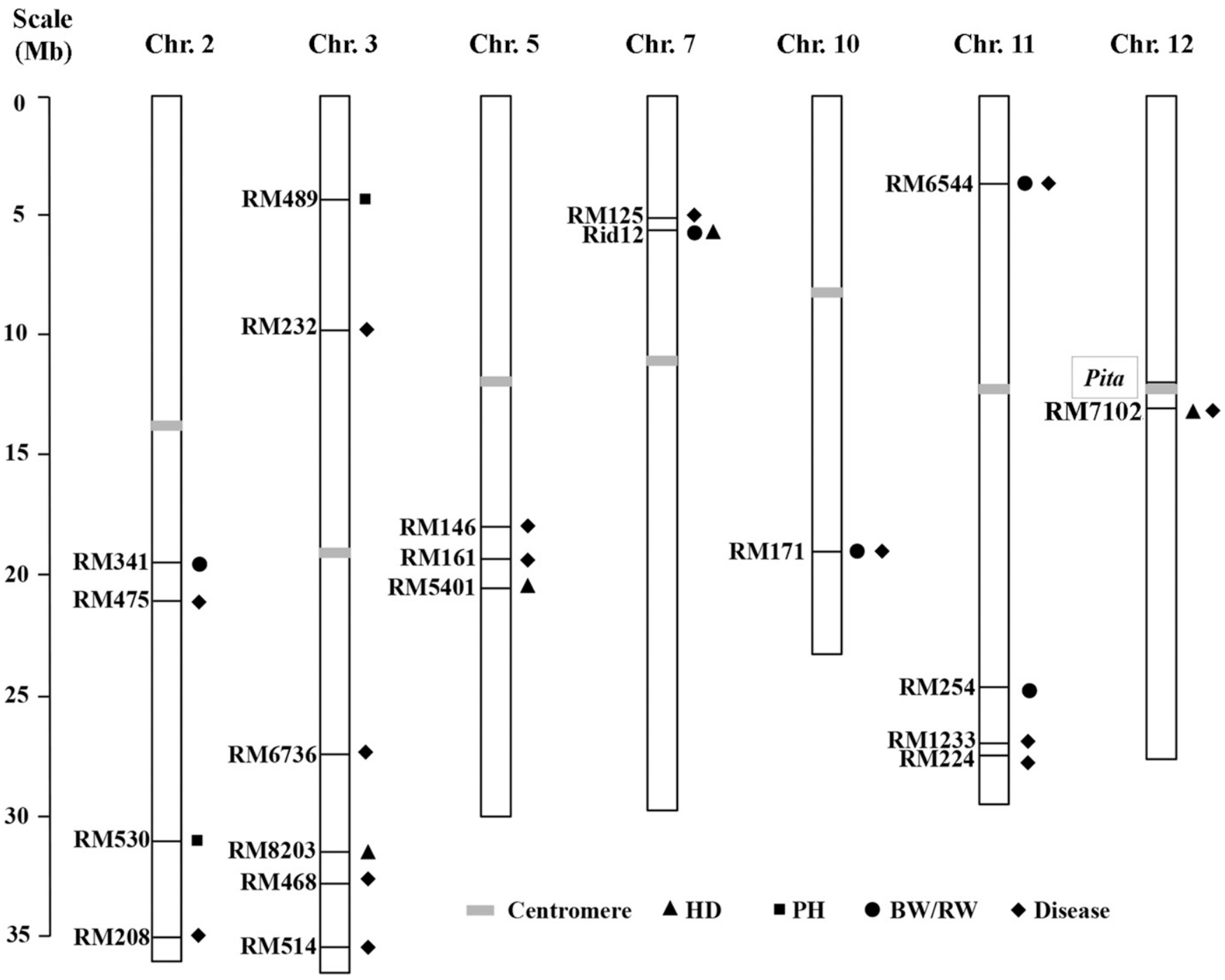

Fig. 5. Rice chromosomes containing linked markers associated with yield components and blast disease. 
incubated in black plastic bags for $24 \mathrm{~h}$ at 21 to $24^{\circ} \mathrm{C}$, were then transferred to the cooling room with an 8-h light and 16-h dark cycle, and were maintained at $80 \%$ relative humidity. The plants were rated on the seventh day postinoculation at the second youngest leaf, using a categorical rating system from 0 to 5 , in which $0=$ no visible lesion, $1=$ a few small point lesions, $2=$ lesion sizes smaller than $2 \mathrm{~mm}$ without obvious fungal mass, $3=$ $10 \%$ of leaf area with lesions $>2 \mathrm{~mm}, 4=>10 \%$ and $<50 \%$ of the leaf area with lesions greater than $3 \mathrm{~mm}$; and $5=>50 \%$ of leaf area with lesions $>3 \mathrm{~mm}$ (RoyChowdhury et al. 2011). One single disease rating score was given to each insert ( 5 to 15 seedlings) and the disease reactions were repeated two to four times. The mean value from three to five disease scores for each accession was used for association and correlation analyses.

The field evaluation was performed at Pine Tree, Arkansas. Rice accessions were completely randomized. Rice was planted in hill drop plots with a spacing of $30 \times 40 \mathrm{~cm}$ with susceptible germplasm and known cultivars included at regular intervals within the nursery. An intermittent shallow flood was used in conjunction with selective application rate and timing of nitrogen fertilizer to favor blast development within the nursery. Large overhead sprinklers supplied occasional simulated rain. Once plants reached the optimum tillering growth stage (V4 to V5) (Counce et al. 2000), artificial inoculations with an evenly distributed mixture of $M$. oryzae races IB-1, IC-17, IB-49, IG-1, IH- 1 , and IE- 1 as spores $\left(5 \times 10^{10}\right.$ to $10 \times 10^{10}$ spores per milliliter) and as cracked corn fragments colonized with these isolates. Inoculations were continued using both methods until significant blast symptoms were observed in spreader plots. Leaf lesions were evaluated using the visual rating scale. Panicle blast was evaluated using a visual 0 to 9 rating scale where $0=$ no symptoms on the flag leaf collar or panicles, $9=$ flag collars, panicles, or both showing severe symptoms. Due to uneven entry maturity, panicle evaluations were made at the R6 to R8 growth stages as early and final panicle blast ratings. Experiments were repeated two to four times, and the mean values of disease scores for each accession were used for association and correlation analysis.

\section{Phenotypic evaluation and correlation analysis.}

Each accession was grown in a plot consisting of three rows, $20 \mathrm{~cm}$ apart and $150 \mathrm{~cm}$ long, with $1 \mathrm{~g}$ of seeds planted in each row, resulting 100 to 120 plants, by Heg 500 planter at the University of Arkansas Rice Research and Extension Center, Stuttgart, Arkansas, in 2002 and 2008. Plots with randomized accessions were separated at $90 \mathrm{~cm}$ to avoid biological and mechanical contamination. Weeds were controlled with Propanil at 1 gallon per acre mixed with Bolero at 2 gallons per acre. A permanent flood established after $60 \mathrm{LB} /$ acre of nitrogen as urea was applied at 5-leaf stage. The agronomic traits including heading days, plant height, paddy and brown seed weight were evaluated using standard criteria, described on the Germplasm Resource Information Network, as heading days $=$ days from seedling emergence to $50 \%$ (100 to 120 plants) of the flowering panicles in a plot and plant height $=$ setting the scale in the center of the plot and measuring length from the ground to the panicle tip at maturity. Plant height and heading dates are measurements of large numbers of plants in a plot. Seed weight $=$ thousand kernel weight, total brown seed weight (after rice hull was removed), or paddy seed weight divided by the total number of kernels multiplied by 1,000 . The Grain Check (Foss Tecator, Hoganas, Sweden) was used for seed weight. The correlation of the phenotypic data with the disease reactions were analyzed with Pearson's correlation matrix at level of 0.95 using the $\mathrm{R}$ environment corplot package.

\section{Genotyping.}

Genomic DNA of each accession was extracted as described by Wang et al. (2008) and was genotyped with 156 SSR markers evenly distributed among the entire rice chromosomes. For each marker, forward primers were labeled with 6FAM, NED, PET, or HEX (Applied Biosystems, Foster City, CA, U.S.A., or Integrated DNA Technologies, Coralville, IA, U.S.A.). The reverse primer was unlabeled. The amplifications were performed using MJ Research Tetrad thermal cyclers (Bio-Rad, Hercules, CA, U.S.A.) with the following program: ii) $95^{\circ} \mathrm{C}$ for $5 \mathrm{~min}$, ii) $95^{\circ} \mathrm{C}$ for $30 \mathrm{~s}$, iii) 55 to $67^{\circ} \mathrm{C}$ for $30 \mathrm{~s}$, iv) $72^{\circ} \mathrm{C}$ for $1 \mathrm{~min}, \mathrm{v}$ ) repeat steps ii to iv for 34 times, and vi) $72^{\circ} \mathrm{C}$ for $10 \mathrm{~min}$. Polymerase chain reaction products were pooled based on color and size range of amplified fragments (typically three markers per run along with the LIZ-labeled size standard), and the DNA was denatured by heating samples at $94^{\circ} \mathrm{C}$ for $5 \mathrm{~min}$. The samples were separated on an ABI Prism 3730 DNA analyzer according to the manufacturer's instructions.

\section{Determination of the $Q$ value.}

The population structure was performed using STRUCTURE software version 2.3.4 (Hubisz et al. 2009; Pritchard et al. 2000). To infer the population structure, 10 independent runs of Q 1 to Q 10 were performed, with a burn-in period of 100,000 and 1,000,000 replicates. Three steps were used to determine the most probable structure number. First, the average value of PD In likelihood of Q1 to Q10 (returned by software) was calculated; second, the delta PD ln was calculated (Evanno et al. 2005), and finally, the variation of the PD $\ln$ of each Q was calculated. The number of the population can be determined by calculating the mean value of Ln PD of each Q from the STRUCTURE software. However, we didn't observe the plateau of $\mathrm{Q}$ value from 1 to 10 . Calculating the delta $\mathrm{Q}$, which related with the change of the likelihood and usually showed a clear peak at the true value of the $\mathrm{Q}$, was also used to estimate the $Q$ value (Evanno et al. 2005). The max delta $Q$ value was observed for $\mathrm{Q}=5$, although two clear peaks appeared. Delta $\mathrm{Q}$ considered the variation among the 10 runs of each $Q$, the peak reflected that the corresponding $\mathrm{Q}$ has higher standard deviation than others. We calculated the variation Ln PD of each $\mathrm{Q}$ within 10 runs, which was returned by the STRUCTURE software. The peak recalled to Q6.

\section{Association mapping.}

Association mapping for plant height and heading date in 2002 and 2008 was analyzed separately to identify common genetic markers associated with these traits. The $\mathrm{Q}$ can result in spurious associations, it has been controlled in our association mapping model: $y=\mathrm{X} \beta+\mathrm{S} \alpha+\mathrm{Q} v+e$, where $y$ is a vector of phenotypic observations, $\beta$ is a vector of fixed effects other than marker under testing or population groups effects, $\alpha$ is a vector of marker effects, $v$ is a vector for population effects, $e$ is a vector of residual effects; Q is a matrix from STRUCTURE relating $y$ to $v$; $\mathrm{X}$ and $\mathrm{S}$ are incidence matrices of $1 \mathrm{~s}$ and 0 s relating $y$ to $\beta$ and $\alpha$, respectively. Beside population structure, incorporating relative kinship (K) through the mixed model (Yu et al. 2006) was also broadly used to reduce false positives. However, this mixed model may overcompensate the association analysis, leading to false negatives (Zhao et al. 2011). To determine the admittance of $\mathrm{K}$ into our association model, the relative kinship of the Pi-ta core population was estimated using SPAGeDi (Hardy and Vekemans 2002). Because only a minimum amount of kinship was detected in this population, $\mathrm{K}$ was excluded. A population structure controlled Q model through the generalized linear model functions of the software TASSEL was used (Bradbury et al. 2007) to run the association analysis. To verify this study, the FDR values of each association marker were calculated using 
Qvalue software, and 0.05 was determined to be the $\mathrm{Q}$ value cutoff for associated markers (Storey et al. 2004).

\section{ACKNOWLEDGMENTS}

We thank the University of Arkansas Rice Research and Promotion Board for the support to F. N. Lee and X. Wang, Natural Science Foundation of China (program number 31000847) and Science Technology Department of Zhejiang Province (program number 2014C32011) for X. Wang, Asia Rice Foundation for supporting X. Wang's partial trave expenses. For critical reviews, we thank K. Yeater and J. Eduard; for the development of RiceBase, we thank A. Baldo and J. Eduard; for technical assistance, we thank T. Beaty, L. Simpson, T. Bianco, M. Lin, and J. C. Jia. The United States Department of Agriculture is an equal opportunity provider and employer.

\section{LITERATURE CITED}

Alexandrov, N., Tai, S., Wang, W., Mansueto, L., Palis, K., Fuentes, R. R., Ulat, V. J., Chebotarov, D., Zhang, G., Li, Z., Mauleon, R., Hamilton, R. S., and McNally, K. L. 2015. SNP-seek database of SNPs derived from 3000 rice genomes. Nucleic Acids Res. 43:D1023-D1027.

Ashikawa, I., Hayashi, N., Yamane, H., Kanamori, H., Wu, J., Matsumoto, T., Ono, K., and Yano, M. 2008. Two adjacent nucleotide-binding siteleucine-rich repeat class genes are required to confer Pikm-specific rice blast resistance. Genetics 180:2267-2276.

Bergelson, J., and Purrington, C. B. 1996. Surveying patterns in the cost of resistance in Plants. Am. Nat. 148:536-558.

Bradbury, P. J., Zhang, Z., Kroon, D. E., Casstevens, T. M., Ramdoss, Y., and Buckler, E. S. 2007. TASSEL: Software for association mapping of complex traits in diverse samples. Bioinformatics 23:2633-2635.

Brown, J. K. M. 2002. Yield penalties of disease resistance in crops. Curr. Opin. Plant Biol. 5:339-344.

Bryan, G. T., Wu, K. S., Farrall, L., Jia, Y., Hershey, H., McAdams, S., Tarchini, R., Donaldson, G., Faulk, K., and Valent, B. 2000. A single amino acid difference distinguishes resistant and susceptible allele of the rice blast resistance gene Pi-ta. Plant Cell 12:2033-2045.

Chen, Y., and Lübberstedt, T. 2010. Molecular basis of trait correlations. Trends Plant Sci. 15:454-461.

Costanzo, S., and Jia, Y. 2010. Sequence variation at the rice blast resistance gene Pi-km locus: Implications for the development of allele specific markers. Plant Sci. 178:523-530.

Counce, P. A., Keisling, T. C., and Mitchell, A. J. 2000. A uniform, objective and adaptive system for expressing rice development. Crop Sci. 40:436-443.

Dangl, J. L., and Jones, J. D. G. 2001. Plant pathogens and integrated defence responses to infection. Nature 411:826-833.

Doi, K., Izawa, T., Fuse, T., Yamanouchi, U., Kubo, T., Shimatani, Z., Yano, M., and Yoshimura, A. 2004. Ehd1, a B-type response regulator in rice, confers short-day promotion of flowering and controls FT-like gene expression independently of $H d 1$. Genes Dev. 18:926-936.

Evanno, G., Regnaut, S., and Goudet, J. 2005. Detecting the number of clusters of individuals using the software STRUCTURE: A simulation study. Mol. Ecol. 14:2611-2620.

Fjellstrom, R. G., Conaway-Bormans, C. A., McClung, A. M., Marchetti, M. A., Shank, A. R., and Park, W. D. 2004. Development of DNA markers suitable for marker assisted selection of three $P i$ genes conferring resistance to multiple Pyricularia grisea pathotypes. Crop Sci. 44:1790-1798.

Fukuoka, S., Saka, N., Koga, H., Ono, K., Shimizu, T., Ebana, K., Hayashi, N., Takahashi, A., Hirochika, H., Okuno, K., and Yano, M. 2009. Loss of function of a proline-containing protein confers durable disease resistance in rice. Science 325:998-1001.

Hardy, O. J., and Vekemans, X. 2002. SPAGeDi: A versatile computer program to analyse spatial genetic structure at the individual or population levels. Mol. Ecol. Notes 2:618-620.

He, P., Li, J., Zheng, X., Shen, L., Lu, C., Chen, Y., and Zhu, L. 2001. Comparison of molecular linkage maps and agronomic trait loci between DH and RIL populations derived from the same rice cross. Crop Sci. 41:1240-1246.

Hittalmani, S., Huang, N., Courtois, B., Venuprasad, R., Shashidhar, H. E., Zhuang, J.-Y., Zheng, K.-L., Liu, G.-F., Wang, G.-C., Sidhu, J. S., Srivantaneeyakul, S., Singh, V. P., Bagali, P. G., Prasanna, H. C., McLaren, G., and Khush, G. S. 2003. Identification of QTL for growthand grain yield-related traits in rice across nine locations of Asia. Theor. Appl. Genet. 107:679-690.

Hubisz, M. J., Falush, D., Stephens, M., and Pritchard, J. K. 2009. Inferring weak population structure with the assistance of sample group information. Mol. Ecol. Resour. 9:1322-1332.
Jia, Y. 2009. Artificial introgression of a large chromosome fragment around the rice blast resistance gene $P i-t a$ in backcross progeny and several elite rice cultivars. Hered. Edinb 103:333-339.

Jia, Y., Jia, M. H., Wang. X., and Liu, G. 2012. Indica and japonica crosses resulting in linkage block and recombination suppression on rice chromosome 12. PLoS ONE 7:10.

Jia, Y., Wang, Z., Fjellstrom, R. G., Moldenhauer, K. A. K., Azam, M. A., Correll, J., Lee, F. N., Xia, Y., and Rutger, J. N. 2004. Rice Pi-ta gene confers resistance to the major pathotypes of the rice blast fungus in the United States. Phytopathology 94:296-301.

Jones, J. D. G., and Dangl, J. L. 2006. The plant immune system. Nature 444:323-329.

Lee, S., Jia, M. H., Jia, Y., and Liu, G. 2014. Tagging quantitative trait loci for heading date and plant-height in important breeding parents of rice (Oryza sativa). Euphytica 197:191-200.

Lee, S., Jia, Y., Jia, M. H., Gealy, D., Olsen, K. M., and Caicedo, A. L. 2011. Molecular evolution of the rice blast resistance gene Pi-ta in invasive weedy rice in the USA. PLoS ONE 6:10.

Li, Z. K., Yu, S. B., Lafitte, H. R., Huang, N., Courtois, B., Hittalmani, S., Vijayakumar, C. H., Liu, G. F., Wang, G. C., Shashidhar, H. E., Zhuang, J. Y., Zheng, K. L., Singh, V. P., Sidhu, J. S., Srivantaneeyakul, S., and Khush, G. S. 2003. QTL x environment interactions in rice. I. heading date and plant height. Theor. Appl. Genet. 108:141-153.

Lin, H., Liang, Z. W., Sasaki, T., and Yano, M. 2003. Fine mapping and characterization of quantitative trait loci $\mathrm{Hd} 4$ and $\mathrm{Hd} 5$ controlling heading date in rice. Breed. Sci. 53:51-59.

Lu, C., Shen, L., He, P., Chen, Y., Zhu, L., Tan, Z., and Xu, Y. 1997. Comparative mapping of QTLs for agronomic traits of rice across environments by using a doubled-haploid population. Theor. Appl. Genet. 94:145-150.

Mather, K. A., Caicedo, A. L., Polato, N. R., Olsen, K. M., McCouch, S., and Purugganan, M. D. 2007. The extent of linkage disequilibrium in rice (Oryza sativa L.). Genetics 177:2223-2232.

Moldenhauer, K. A. K., Gibbons, J. W., Lee, F. N., Bernhardt, J. L., Wilson, C. E., Anders, M. M., Blocker, M. M., Tolbert, A. C., Taylor, K., and Bulloch, J. M. 2007. Registration of 'Francis'. Rice. Crop Sci. 47: 443-444.

Pinson, S. R. M., Jia, Y., and Gibbons, J. 2012. Response to early generation selection for resistance to rice kernel fissuring. Crop Sci. 52:1482-1492.

Pritchard, J. K., Stephens, M., and Donnelly, P. 2000. Inference of population structure using multilocus genotype data. Genetics 155: 945-959.

RoyChowdhury, M., Jia, Y., Jackson, A., Jia, M. H., Fjellstrom, R., and Cartwright, R. D. 2011. Analysis of rice blast resistance gene Pi-z using pathogenicity assays and DNA markers. Euphytica 184:35-47.

RoyChowdhury, M., Jia, Y., Jia, M. H., Fjellstrom, R., and Cartwright, R. D. 2012. Identification of the rice blast resistance gene $P i b$ in the National Small Grains Collection. Phytopathology 102:700-706.

Septiningsih, E. M., Prasetiyono, J., Lubis, E., Tai, T. H., Tjubaryat, T., Moeljopawiro, S., and McCouch, S. R. 2003. Identification of quantitative trait loci for yield and yield components in an advanced backcross population derived from the Oryza sativa variety IR64 and the wild relative O. rufipogon. Theor. Appl. Genet. 107:1419-1432.

Sharma, T. R., Madhav, M. S., Singh, B. K., Shanker, P., Jana, T. K., Dalal, V., Pandit, A., Singh, A., Gaikwad, K., Upreti, H. C., and Singh, N. K 2005. High-resolution mapping, cloning and molecular characterization of the Pi-kh gene of rice, which confers resistance to Magnaporthe grisea. Mol. Genet. Genomics 274:569-578.

Smedegaard-Petersen, V., and Tolstrup, K. 1985. The limiting effect of disease resistance on yield. Annu. Rev. Phytopathol. 23:475-490.

Spielmeyer, W., Ellis, M. H., and Chandler, P. M. 2002. Semidwarf (sd-1), "green revolution" rice, contains a defective gibberellin 20-oxidase gene. Proc. Natl. Acad. Sci. U.S.A. 99:9043-9048.

Spindel, J., Begum, H., Akdemir, D., Virk, P., Collard, B., Redoña, E., Atlin, G., Jannink, J. L., and McCouch, S. R. 2015. Genomic selection and association mapping in rice (Oryza sativa): Effect of trait genetic architecture, training population composition, marker number and statistical model on accuracy of rice genomic selection in elite, tropical rice breeding lines. PLoS Genet. 11:e1004982.

Storey, J. D., Taylor, J. E., and Siegmund, D. 2004. Strong control, conservative point estimation, and simultaneous conservative consistency of false discovery rates: A unified approach. J. Roy. Stat. Soc. B 66:187-205.

Storey, J. D., and Tibshirani, R. 2003. Statistical significance for genomewide studies. Proc. Natl. Acad. Sci. U.S.A. 100:9440-9445.

Tanabata, T., Shibaya, T., Hori, K., Ebana, K., and Yano, M. 2012. SmartGrain: High-throughput phenotyping software for measuring seed shape through image analysis. Plant Physiol. 160:1871-1880. 
Thomson, M. J., Tai, T. H., McClung, A. M., Lai, X. H., Hinga, M. E., Lobos, K. B., Xu, Y., Martinez, C. P., and McCouch, S. R. 2003. Mapping quantitative trait loci for yield, yield components and morphological traits in an advanced backcross population between Oryza rufipogon and the Oryza sativa cultivar Jefferson. Theor. Appl. Genet. 107:479-493.

Tian, D., Traw, M. B., Chen, J. Q., Kreitman, M., and Bergelson, J. 2003. Fitness costs of $R$-gene-mediated resistance in Arabidopsis thaliana. Nature 423:74-77.

Wang, X., Fjellstrom, R., Jia, Y., Yan, W. G., Jia, M. H., Scheffler, B. E., Wu, D., Shu, Q., and McClung, A. 2010. Characterization of Pi-ta blast resistance gene in an international rice core collection. Plant Breed. 129: 491-501.

Wang, X., Jia, Y., Shu, Q., and Wu, D. 2008. Haplotype diversity at the Pi-ta locus in cultivated rice and its wild relatives. Phytopathology 98: 1305-1311.

Wang, X. S., Lee, J., Wang, J., Ma, Bianco, T., and Jia, Y. 2014. Current advances on genetic resistance to rice blast disease. Pages 195-217 in: Rice - Germplasm, Genetics and Improvement. Y. Wengui and B. Jinsong. InTech, Rijeka, Croatia. doi: 10.5772/56824. Published online.

Wang, Z. X., Yano, M., Yamanouchi, U., Iwamoto, M., Monna, L., Hayasaka, H., Katayose, Y., and Sasaki, T. 1999. The Pib gene for rice blast resistance belongs to the nucleotide binding and leucinerich repeat class of plant disease resistance genes. Plant J. 19: 55-64.
Yan, J., Zhu, J., He, C., Benmoussa, M., and Wu, P. 1998. Molecular dissection of developmental behavior of plant height in rice (Oryza sativa L.). Genetics 150:1257-1265.

Yu, J., Pressoir, G., Briggs, W. H., Vroh Bi, I., Yamasaki, M., Doebley, J. F., McMullen, M. D., Gaut, B. S., Nielsen, D. M., Holland, J. B., Kresovich, S., and Buckler, E. S. 2006. A unified mixed-model method for association mapping that accounts for multiple levels of relatedness. Nat. Genet. 38:203-208.

Yuan, B., Zhai, C., Wang, W., Zeng, X., Xu, X., Hu, H., Lin, F., Wang, L., and Pan, Q. 2011. The Pik-p resistance to Magnaporthe oryzae in rice is mediated by a pair of closely linked CC-NBS-LRR genes. Theor. Appl. Genet. 122:1017-1028.

Zhai, C., Lin, F., Dong, Z., He, X., Yuan, B., Zeng, X., Wang, L., and Pan, Q. 2011. The isolation and characterization of Pik, a rice blast resistance gene which emerged after rice domestication. New Phytol. 189:321-334.

Zhao, K., Tung, C. W., Eizenga, G. C., Wright, M. H., Ali, M. L., Price, A. H., Norton, G. J., Islam, M. R., Reynolds, A., Mezey, J., McClung, A. M., Bustamante, C. D., and McCouch, S. R. 2011. Genome-wide association mapping reveals a rich genetic architecture of complex traits in Oryza sativa. Nat. Commun. 2:467.

\section{AUTHOR-RECOMMENDED INTERNET RESOURCE}

The R Project for Statistical Computing software: http://www.r-project.org 